This paper is based on the first George Brown Lecture delivered at the Clay Minerals Group Meeting held at the University of Exeter on 6th April 2000.

\title{
Order-disorder in clay mineral structures
}

\author{
A. PLANÇON* \\ ISTO, CNRS-Université d'Orléans, 1 A rue de la Férollerie, 45071 Orléans, Cedex 2, France
}

(Received 6 April 2000; revised 24 July 2000)

\begin{abstract}
Some recent works dealing with the concept of order-disorder in clay minerals are considered, including those aspects of order-disorder which appeared in the Brindley \& Brown (1980) monograph, i.e. disorder in the distribution of cations, disorder in layer stacking, orderdisorder in mixed-layer systems and finite crystal size as a lattice disorder. Heterogeneity of samples and polymorphous transformations are also considered as other types of disorder. Most of these works emphasize that accurate structural characterization can only be obtained if several techniques are combined (e.g. XRD and IR, EXAFS and Mössbauer spectroscopies, etc.). Another conclusion is that accurate structural determination provides the key to the genesis of clays.
\end{abstract}

KEYWORDs: order, disorder, phyllosilicates, clay minerals, cation distribution, heterogeneity, mixed layer.

Clay minerals can be described very simply by the stacking of two kinds of layers: 1:1 layers and 2:1 layers. In fact these layers can have a very wide range of chemical compositions, of distributions of isomorphous cations, and can stack in a lot of different ways, including mixed layering. Their structural triperiodicity is the exception, in which case description involves the order-disorder concept. On the other hand, these minerals have the ability to evolve, e.g. to change their layer or interlayer cations, to sustain polymorphous transformations by octahedral cation migration, to modify the stacking of the layers, and even to change the type of the layers, from 1:1 into $2: 1$ for example. The variety of clay minerals induces the variety in their properties. Accurate determination of the structural characteristics leads to a clearer understanding of, and improvements in, the prediction of the properties of clays.

The aim of this paper is not to reconsider, in an exhaustive way, what has been published about the

* E-mail: Alain.Plancon@univ-orleans.fr structural characterization of clay minerals, the mechanisms by which they change when they are subjected to different physical or chemical stresses and the correlation between structure and properties. The aim is rather to review the most recent papers published on these topics, to show what the 'state of the art' is.

The classical division of order-disorder which appeared in the Brindley \& Brown (1980) monograph will be retained here, i.e. disorder in distribution of cations, disorder in layer stacking, long-range and short-range order, order-disorder in mixed-layer systems, finite crystal size as a lattice disorder, adding the polymorphous transformations and heterogeneity of the sample as two other types of disorder.

\section{THE DIFFERENT TYPES OF ORDER-DISORDER}

\section{Order-disorder in mixed-layer systems}

Serpentine to chlorite transformation. It is known that serpentine (S) transforms into chlorite (C), and vice versa (Bailey, 1988), and that random 
serpentine-chlorite interstratifications occur. Regularly interstratified serpentine-chlorite also exists such as $\mathrm{S}_{1} \mathrm{C}_{1}$ (dozyite), $\mathrm{S}_{2} \mathrm{C}_{1}, \mathrm{~S}_{3} \mathrm{C}_{1}, \mathrm{~S}_{1} \mathrm{C}_{2}$, $\mathrm{S}_{1} \mathrm{C}_{3}$ (Banfield et al., 1994; Bailey et al., 1995). It was not known why these long-period, regularly interstratified varieties crystallize instead of discrete serpentine or chlorite or a random interstratification of these. Normal coulombic interactions are unlikely to allow structural communication on such large scales. This problem was clarified by Banfield \& Bailey (1996) who studied several specimens from the Woods Chrome Mine, Lancaster County, Pennsylvania, by high-resolution transmission electron microscopy (HRTEM) with a point resolution of $\sim 0.19 \mathrm{~nm}$. They observed that regularly interstratified $\mathrm{S}-\mathrm{C}$ are frequently intimately intergrown with serpentines that have repeat distances identical to those of the regular interstratification (Fig. 1). For example, dozyite $\mathrm{S}_{1} \mathrm{C}_{1}$ is intimately associated with three-layer octahedral order I,I,II (where II represent an octahedral sheet of the serpentine layer rotated by $180^{\circ}$ with respect to I). Longer period polymorphs $\left(\mathrm{S}_{2} \mathrm{C}_{1}, \mathrm{~S}_{1} \mathrm{C}_{2}, \mathrm{~S}_{2} \mathrm{C}_{2}, \mathrm{~S}_{3} \mathrm{C}_{2}\right.$ and $\mathrm{S}_{1} \mathrm{C}_{4}$, all with $\left.\beta=90^{\circ}\right)$ are each accompanied by serpentines with equivalent $c$-axis periodicities. They apparently form by the selective growth of $I b$ chlorite units from I,II octahedral sequences in long-period serpentines. For

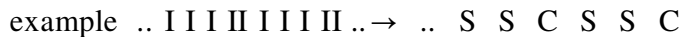
..(S2C1) or .. I I II I II I I II .. $\rightarrow$ S C C S C ... Because polytypes differ in their octahedral tilt sequences they almost certainly have different structural energies and should exhibit differential stability, which explains why I,II sequences are converted selectively into chlorite.

Microscopic studies are consistent with the formation of regular interstratification by tetrahedral inversion within existing serpentine. Atomic resolution images reveal that the tetrahedral sheet is displaced by $a / 3$ where it inverts to form the $2: 1$ layer. $\mathrm{A} \pm a / 3$ shift is required for hydrogen bonding between $\mathrm{OH}$ of the newly-formed brucitelike interlayer and $\mathrm{O}$ atoms of the newly-formed 2:1 layer. The sense of the shift is determined by the strong interaction between the octahedral cations in the brucite-like interlayer and the $\mathrm{Si}$ in the $2: 1$ layer, because direct superimposition is strongly unfavourable. Distortion at the inversion point probably lengthens $\mathrm{Si}-\mathrm{O}$ bonds in the next tetrahedron, facilitating the relocation of $\mathrm{Si}$ on the other side of the basal $\mathrm{O}$ plane. The reversal of the octahedral slant in the 2:1 layer occurs because the $+a / 3$ tetrahedral shift necessitates the repositioning of $\mathrm{O}-$ and $\mathrm{OH}$-coordinating octahedral cations, requiring movement of the octahedral cations from type-II to type-I positions. Except for the 2:1 layers, the stacking and octahedral slants are inherited.

Conversion of smectite into kaolinite. The existence of mixed-layer kaolinite-smectites has been known for some time (Sudo \& Hayashi, 1956). Using X-ray diffraction (XRD) they were described as randomly interstratified layers (Schultz et al., 1971; Wiewiora, 1971) and as 1-1 ordered interstratification (Thomas, 1989). Although the direct observation of the individual layers is possible with HRTEM, no such study had been performed for interlayered kaolinite-smectite until recently, probably because the minerals formed during a weathering alteration process are poorly crystallized and difficult to characterize. Amouric \& Olives (1998) reconsidered this problem, using a low-light camera equipped with an yttrium aluminium garnet in order to minimize possible beam damage. Two types of smectite crystals were observed: $\mathrm{S}$, which gives images showing only $1 \mathrm{~nm}$ fringes and another, $\mathrm{S}^{\prime}$ where $1.25 \mathrm{~nm}$ fringes are spaced evenly. In addition to these smectite crystals, mixed-layer kaolinite-smectite was also observed. Three samples from the Paris basin were studied with 10, 45 and $60 \%$ kaolin layers. The relative abundance of $S^{\prime}$ layers compared to the $S$ layers increases as the percentage of $\mathrm{K}$ increases. In the $10 \%$ and $45 \%$ kaolinite samples the lateral transitions of one smectite layer into one kaolinite layer are visible in images, the $1 \mathrm{~nm}$ smectite fringes prevailing in the $10 \%$ kaolinite sample. In the $60 \%$ kaolinite sample, another type of lateral change is also observed: the transition of a $S^{\prime}$ layer into a $\mathrm{KS}^{\prime}$ unit, which can be interpreted as the partial intercalation of one kaolinite layer in smectite.

Two solid-state mechanisms seem to be responsible for the formation of kaolinite: (1) the transformation of 1 smectite layer into 1 kaolinite layer, by stripping a tetrahedral sheet and the adjacent interlayer region (Fig. 2); and (2) the intercalation of 1 kaolinite layer into smectite.

Determination of illite-smectite structures. The determination of the structure of illite-smectite (I-S) is important because these are common minerals whose structure changes through diagenesis, weathering and hydrothermal activity. The interstratification is usually estimated from peak migration curves in XRD patterns (Drits \& Sakharov, 1976; 


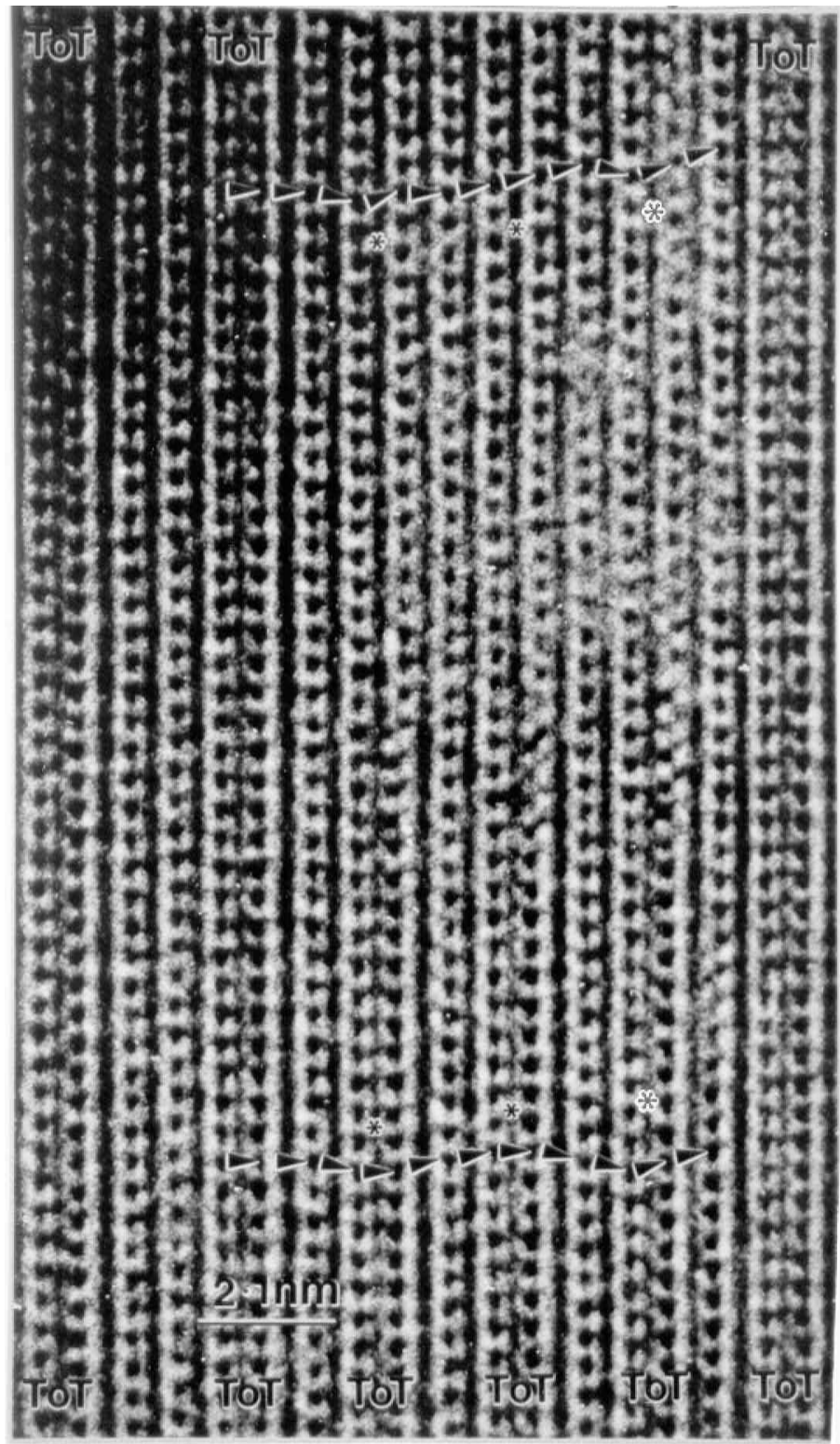

FIG. 1. HRTEM structural image down [100], illustrating serpentine 1:1 layers (top centre) passing smoothly into dozyite. Asterisks mark continuous layers in which the stacking sequences differ. Note that changes in stacking occur at the point of tetrahedral inversion, where two 1:1 layers pass into a chlorite unit (from Banfield \& Bailey, 1996).

Środoń, 1980, 1981, 1984; Watanabe, 1981, 1988; Reynolds, 1981, 1988; Tomita et al., 1988; Moore \& Reynolds, 1989; Drits et al., 1994). This technique can, however, be used for two-component $\mathrm{I}-\mathrm{S}$ with random (Reichweite $\mathrm{R}=0$ ), or maximum ordering for $\mathrm{R}=1,2$ or 3 , but not for segregated $\mathrm{I}$ or $\mathrm{S}$ layers or with intermediate degrees of ordering. Moreover these curves have mainly been used for glycolated I-S assuming that all smectite interlayers contain two glycol layers and that their 

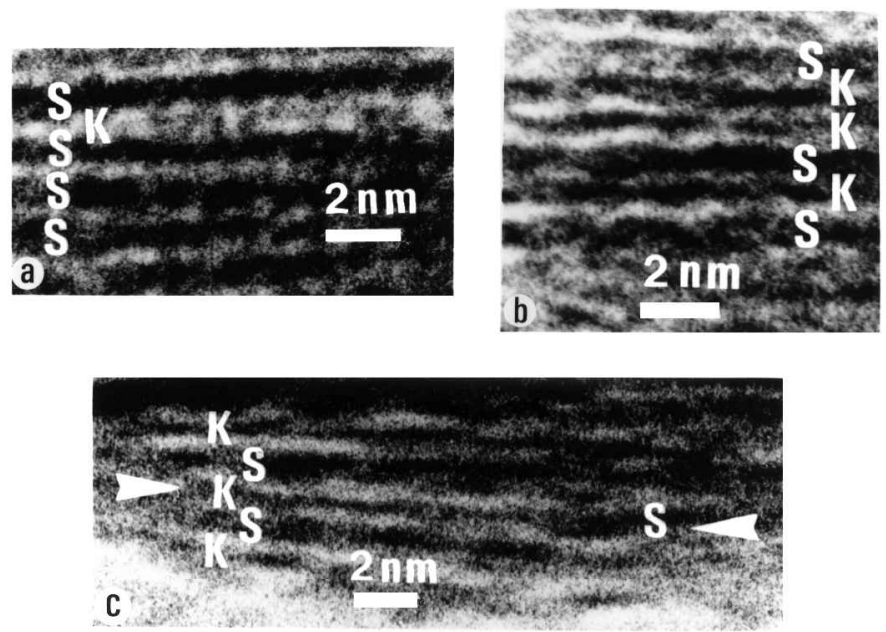

FIG. 2. Lattice fringe images of various interstratified kaolinite-smectites of the $10 \%$ kaolinite sample. $\mathrm{S}=\mathrm{S}$ type smectite layer $(1 \mathrm{~nm}$ thick). $\mathrm{K}=$ kaolinite layer $(0.72 \mathrm{~nm}$ thick). In part $\mathrm{c}$, the lateral transition $\mathrm{S} \rightarrow \mathrm{K}$ is indicated by arrows (from Amouric \& Olives, 1998).

swelling properties do not depend on the interlayer cation. The most efficient technique for the determination of the structural parameters is based on the comparison between experimental XRD curves and patterns calculated for structural models having different proportions and distributions of I and S (Reynolds \& Hower, 1970; Drits \& Sakharov, 1976; Reynolds, 1980; Moore \& Reynolds, 1989; Drits \& Tchoubar, 1990). However, the simulation of XRD patterns requires many structural and instrumental parameters. The effect of these numerous variables is that several structural models may fit the experimental data equally well, especially if the experimental and calculated patterns are not superposed.

Sakharov et al. (1999b) showed that reliable structural models can be obtained if a multi-specimen profile-fitting procedure is performed. For each sample, specimens saturated with different cations $(\mathrm{Na}, \mathrm{Mg}$ and $\mathrm{Ca}$ ) are analysed, both air-dried and glycolated. One structural model fitting all the observed patterns then provides the structure of the sample. For example, in case of a North Sea sample, the structural models for the $\mathrm{Ca}-\mathrm{Mg}-$ and $\mathrm{Na}-$ saturated, air-dried specimens have $14.0 \AA$ and $12.5 \AA$ expandable layers with the proportions 0.12 and 0.08 ( $\mathrm{Mg}$ saturated), 0.10 and 0.10 (Ca saturated), and 0.06 and 0.14 ( $\mathrm{Na}$ saturated) (Fig. 3). For the $\mathrm{NH}_{4}^{+}$-saturated specimen, the amount of non-swelling layers is 0.90 but 0.10 of these layers have $d(001)=10.33 \AA$. For all these models the layer types are distributed at $R=1$. This North Sea sample is in fact a four component I-S-V$\mathrm{V}^{\prime}$, where $\mathrm{S}$ and $\mathrm{V}$ are layers which, in the glycolated state, with each of the exchangeable cations, swell to 16.6-17.2 $\AA$ and 12.9-13.6 $\AA$, respectively and where $\mathrm{V}^{\prime}$ (referred to as 'low-charge vermiculite', or 'high-charge smectite'), has the swelling characteristics of smectite or vermiculite, depending on the exchangeable cation, which confirms the data published previously (Drits et al., 1997c). For this sample, the abundances of illite and vermiculite are $w_{\mathrm{I}}=0.80$ and $w_{\mathrm{V}}=0.08$ respectively, while $w_{\mathrm{S}}+w_{\mathrm{V}^{\prime}}$ $=0.12$. In $\mathrm{Mg}$ - or Ca-saturated specimens, both glycolated and air dried, $\mathrm{V}^{\prime}$ swells like smectite, but behaves like $\mathrm{V}$ in Na-saturated and glycolated specimens. Thus, the interpretation of XRD data from dioctahedral mica-smectite minerals requires the analysis of the positions as well as of the intensities of all the basal reflections in the observed XRD patterns and the interpretation of the XRD patterns of glycolated samples may be erroneous if it is based on the qualitative analysis of a single XRD pattern from a Na-saturated sample.

Mechanism of the diagenetic transformation of the I-S-V phases. Illitization is a phenomenon that occurs in various geological environments: bentonites, hydrothermally-altered rocks, shales, etc. 

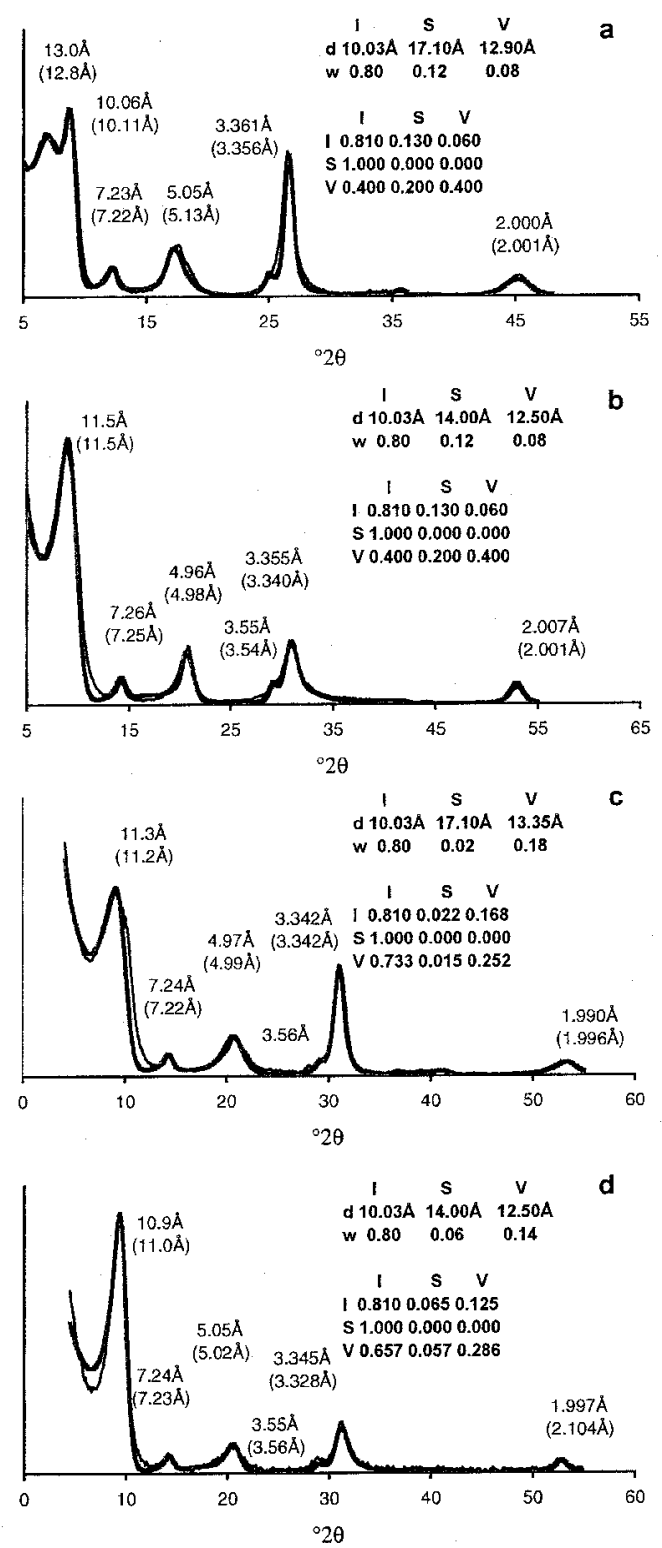

FIG. 3. Powder XRD pattern of North Sea Upper Jurassic shale sample from well 2/11-1, $4548 \mathrm{~m}$ depth (sample 87). The observed and simulated patterns are shown as solid and shaded lines, respectively, with the $d$-values of simulated patterns in brackets. The I-S-V parameters are given above each pattern. Oriented specimens: (a) $\mathrm{Mg}^{2+}$-saturated and glycolated, $\mathrm{Cu}-\mathrm{K \alpha}$ radiation; (b) $\mathrm{Mg}^{2+}$-saturated and air dried, Co- $K \alpha$ radiation; (c) $\mathrm{Na}^{+}$-saturated and glycolated, $\mathrm{Co}-\mathrm{K} \alpha$ radiation; (d) $\mathrm{Na}^{+}$-saturated and air dried, $\mathrm{Co}-K \alpha$ radiation (from Sakharov et al., 1999).
However, the structural mechanism of illitization, via interstratified I-S may be different, depending on each specific set of physicochemical conditions. A review of illitization processes was given by Altaner \& Ylagan (1997), with a description limited to the Reichweite and the abundances of illite and smectite layers, which can be sufficient for bentonites and hydrothermally-altered rocks, but not in the more complex case of shales, for which a multispecimen approach is required. Mixed-layer clay fractions from the North Sea and Denmark were studied using XRD by Drits et al. (1997c). The patterns were computer simulated with the multicomponent program described above. Based on structural characteristics and the degree of diagenetic transformation, the samples that were analysed can be divided into three groups. The I-S-V of group one is predominantly detrital and has $0.69-0.73$ illite, $0.26-0.20$ smectite and 0.04-0.07 vermiculite interlayers, the illite, smectite and vermiculite interlayers being segregated. The I-S-V of group two has been transformed diagenetically and has 0.80 illite, 0.12 smectite and 0.08 vermiculite interlayers, the vermiculite interlayers being segregated whereas the illite and smectite have the maximum ordering possible of $\mathrm{R}=1$. The $\mathrm{I}-\mathrm{S}-\mathrm{V}$ of group three has been transformed further during diagenesis and has 0.84 illite, 0.08 smectite and 0.08 vermiculite interlayers. To understand the structural transformation, the occurrence probabilities $w_{i j}$ and $w_{i j k}(i, j, k=\mathrm{I}, \mathrm{S}$, V) of pairs and triples have been calculated. If each member of the series was formed from the preceding member by a solid-state transformation mechanism, a single interlayer transformation (SIT), then a decrease in amount of definite layer pairs, triples, etc. in one member should increase the amount of layer pairs, triples, etc. of other types in such a way that a new set of occurrence probabilities $w_{i j}, w_{i j k}$, etc. will be equal to that of the next member of the series. Because $\mathrm{R}=1$, the probability of transformation of one definite type of layer pair into another should be constant for a given sample, and does not depend on the preceding and following layer types. This is the case. For example, for the second stage of the I-S-V transformation, smectite interlayers decrease from 0.20 to 0.12 and are transformed into 0.01 vermiculite and 0.07 illite layers. A remarkable feature of this stage is that all the SS pairs are transformed, $77 \%$ into IS, $14 \%$ into SI and the rest into VS and VI. The SV pairs are also totally 
transformed into IV (80\%) and VI (20\%). As a result the tendency to segregation is changed into the maximum possible alternation of illite and smectite interlayers.

The lack of further transformation of vermiculite into illite is surprising because vermiculite interlayers have a higher layer charge than smectite interlayers, and the negative charge of the corresponding expandable interlayers must increase during the formation of illite interlayers. According to Sudo et al. (1962), Drits (1966), Tettenhorst \& Johns (1966), Drits \& Sakharov (1976), Güven (1991) and Jakobsen et al. (1995), 2:1 layers in dioctahedral interstratified minerals have a polar character. Accordingly a neoformation of illite or vermiculite interlayers should take place through a lateral replacement of smectite interlayers including an increase of $\mathrm{Al}$ in the tetrahedral sheets. The different reactivity of $\mathrm{S}$ and $\mathrm{V}$ interlayers to a transformation to illite may be due to the SIT mechanism. After the first stage of transformation, the vermiculite interlayers quickly absorb $\mathrm{K}^{+}$ cations and collapse, thus being closed to further reaction. The source of $\mathrm{Al}$ may be a dissolved K-I-V, containing mainly $\mathrm{K}$, which represents $\sim 10 \%$ of the clay fraction in the group I samples and decreases through the series to group III. It is also noticeable that the newly-formed non-expanding mica interlayers are pure ammonium tobelite, the ammonium probably being supplied by the organic matter during oil occurrence (Drits et al., 1997a). So, statistical calculations demonstrate that the I-S-V transformation in shales can be described as a SIT within crystallites.

\section{Order-disorder in the distribution of cations}

The determination of the actual octahedral cation distribution in dioctahedral micas is a complex problem. X-ray diffraction provides only the average composition of cations in the unit-cell sites. Spectroscopic methods are particularly useful in this instance, since they probe local atomic environments and have the potential to determine short-range cation ordering, each with its own advantages and limitation and therefore providing only a partial solution. A new methodological approach has combined XRD and IR spectroscopy with other methods such as Mössbauer, EXAFS or polarized EXAFS. Thus, the two-dimensional distribution for every type of cation in dioctahedral 2:1 layer silicates has been determined by the computer simulation of the distribution (Dainyak et al., 1992), using experimental data obtained by different spectroscopic methods, with IR data as the basis. A feature of the IR spectra of dioctahedral micas in the $\mathrm{OH}$-stretching region is that each definite pair of cations bonded to an $\mathrm{OH}$ group has a definite position for the corresponding $\mathrm{OH}$ band, whereas the content of a cationic pair is determined by the integrated optical density (Slonimskaya et al., 1986; Besson \& Drits, 1997a,b). This technique provides information on cation distribution at the one-dimensional level only, i.e. for one crystallographic direction, e.g. the $b$ direction for minerals made up of trans-vacant 2:1 layers. Description of the two-dimensional distribution requires us: (1) to specify the degree of preference for one of the two cis-positions (in a half unit-cell) for every cation; and (2) to provide additional information on the limitations imposed on the cation pairs along $b_{1}$ and $b_{2}$ which are the directions running at $\pm 120^{\circ}$ with respect to the $b$ direction. The simulation program was developed to produce the multiple random filling of a honeycomb pattern with cation pairs, leading to different $N_{\mathrm{Fe}}$ (number of $\mathrm{Fe}$ cations around an Fe cation) contents. Those for which $N_{\mathrm{Fe}}$ values are close to that obtained using EXAFS are retained, and for each of them a theoretical Mössbauer spectrum is calculated and compared to the experimental one. The best fit of this Mössbauer pattern provides the best cation distribution. Using this approach, Drits et al. (1997d) analysed different Fe-rich samples (glauconites, Fe-illite and celadonites), and found that $R^{2+}$ cations prefer to occupy one of two symmetrically independent cis-sites in order to maximize the local compensation of anion charges, and, in addition, $R^{2+} R^{2+}$ and/or Fe- $\mathrm{Al}$ are prohibited in the $b_{1}$ and $b_{2}$ directions. Under these conditions, the octahedral sheets of samples show domain structures, i.e. they are represented by domains of various sizes with almost pure $\mathrm{Al}$ or $\mathrm{Fe}^{3+}$ compositions, and by domains of mixed-cation composition (Fig. 4). Other good examples of the usefulness of the combination of several methods are found in Muller et al. (1997), using EXAFS as a basis plus XRD and IR. They showed that in CampBerteaux montmorillonite, $\mathrm{Fe}$ and $\mathrm{Mg}$ cations are segregated in small clusters, and that the heating of samples at temperatures $>150^{\circ} \mathrm{C}$ is accompanied by the migration of $\mathrm{Ni}$ cations into cis-vacant octahedra. Using polarized EXAFS as a basis, Manceau et al. (2000) determined the cation distribution in Swa- 1 nontronite. 


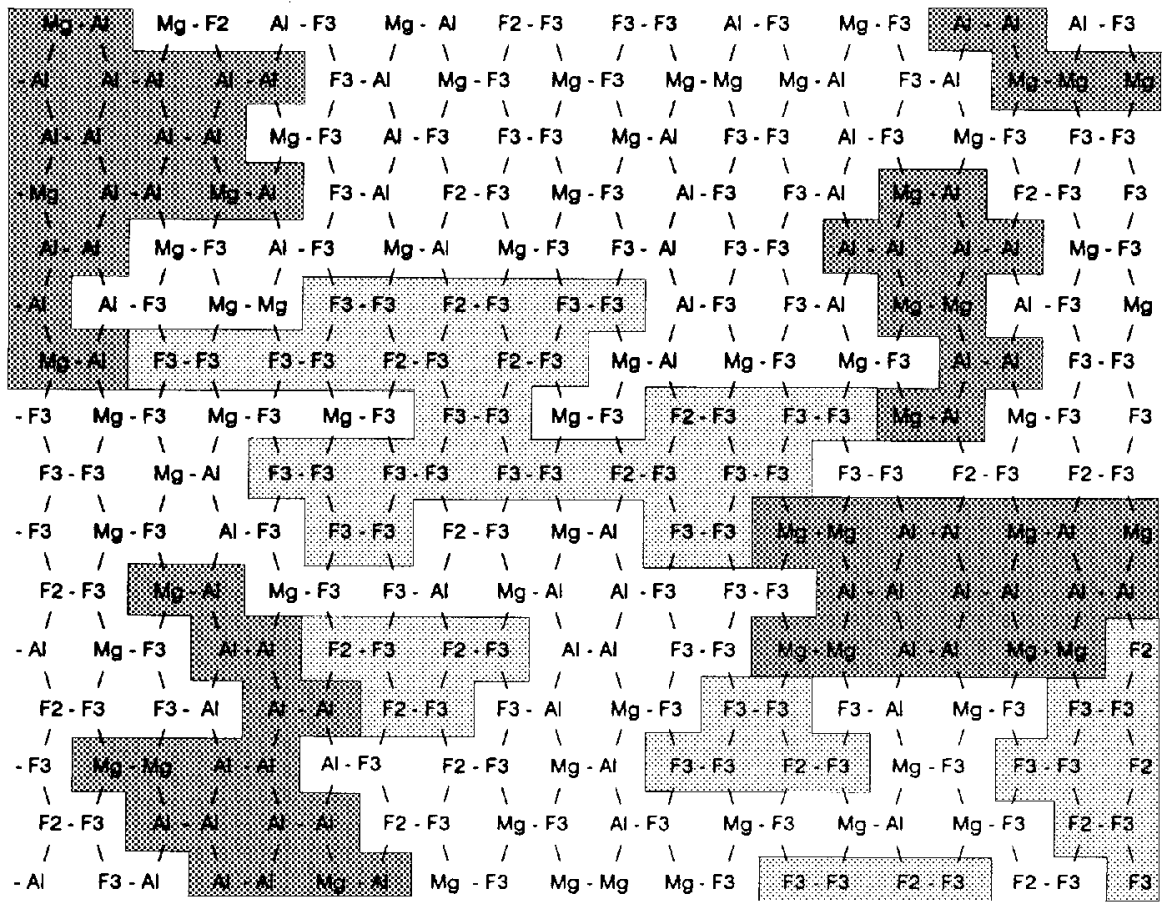

FIG. 4. Two-dimensional cation distribution determined for celadonite sample 68/69 (from Drits et al., 1997).

\section{Polymorphous transformations}

Semiquantitative determination of trans-vacant and cis-vacant layers in illite-smectites and illitesmectite-vermiculites. Interstratified I-S and I-S-V representing both hydrothermal and diagenetic transformations and different degrees of structural order were investigated by Drits et al. (1998) for cis-/trans-occupancy in the octahedral sheet using XRD and differential thermal analysis (DTA) in combination with evolved water analysis (EWA) using an IR detector. By XRD, the amounts of cisvacant ( $c v)$ and trans-vacant ( $t v)$ layers were determined for ordered samples both by the simulation of the patterns and calculations based on the position of $11 l$ reflections (Drits \& McCarty, 1996). If the EWA peaks below and above $600^{\circ} \mathrm{C}$ are attributed to $t v$ and $c v$ octahedra, respectively, the proportions of $c v$ layers $\left(w_{c v}\right)$, determined by XRD and EWA are in agreement. For disordered samples, having no diagnostic $11 l$ reflection, the EWA method is the only one that can be applied.
Tsipurski \& Drits (1984) showed that the 2:1 layers of montmorillonite are $c v$ as a rule, whereas illites normally have $t v$ 2:1 layers. Studying I-S from 28 bentonite samples, Cuadros \& Altaner (1998) also observed that smectitic I-S tend to be $c v$ and become increasingly $t v$ with increasing illitization. The evaluation of $w_{c v}$ shed light on the mechanism of illitization in various geological environments. A decrease in $w_{c v}$ during illitization is probably due to a dissolution precipitation, whereas an almost constant value indicates a solid-state transformation. By way of illustration, Deconinck \& Chamley (1995) found two types of smectitic minerals in the Upper Cretaceous chalks of northern France. The first type contains $65-95 \%$ smectite layers, has a dehydroxylation peak at $\sim 500^{\circ} \mathrm{C}$ and was assumed to originate from continental weathering. The second type contains $90-100 \%$ smectite layers, has a dehydroxylation peak at $600-700^{\circ} \mathrm{C}$ and was interpreted as authigenic. From the results above, the first type must have $t v$ layers which confirms a weathering of mica or illite. The second type, 
assumed to be authigenic, effectively has the $c v$ layers normally found in smectite.

Cation migration during dehydroxylation-rehydroxylation process. The stuctural modification of the 2:1 dioctahedral layer silicates during a dehydroxylation-rehydroxylation process depends both on the original occupancy of trans- and cissites and on the chemical composition of the octahedral sheet. The simplest case is that of $t v$ Al-rich octahedral sheets (most illites). It is known after Udagawa et al. (1974) that their dehydroxylation induces the replacement of two adjacent $\mathrm{OH}$ groups by a residual oxygen located in the plane of the cations, midway between them. The rehydroxylation of these minerals restores the initial structure. For Fe-rich layer silicates a cation migration occurs during dehydroxylation (Tsipurski \& Drits, 1984). Using models generated from powder XRD patterns, selected area electron diffraction (SAED), and thermogravimetric analysis, Muller et al. (1999a, 2000a,b) showed that the mechanism is more complex for $t v \mathrm{Fe}$-, Mg-rich minerals (like celadonite and glauconites). In this case the dehydroxylation causes a migration of $\mathrm{Fe}$ and $\mathrm{Mg}$ cations which leads to a fair distance between cations and a good screening of their repulsion. The migration takes place through the shared edges in the [010] and [310] directions. Depending on the dehydroxylation temperature, primitive unit cells or super-cells are observed in SAED patterns. The existence of additional satellites in the patterns of some crystals heated to $750^{\circ} \mathrm{C}$ corresponds to the existence of antiphase domains with a $3 b / 2$ width and an antiphase shift of $a / 2$. The rehydroxylation of celadonite preserves the octahedral cation distribution formed after dehydroxylation (Fig. 5),

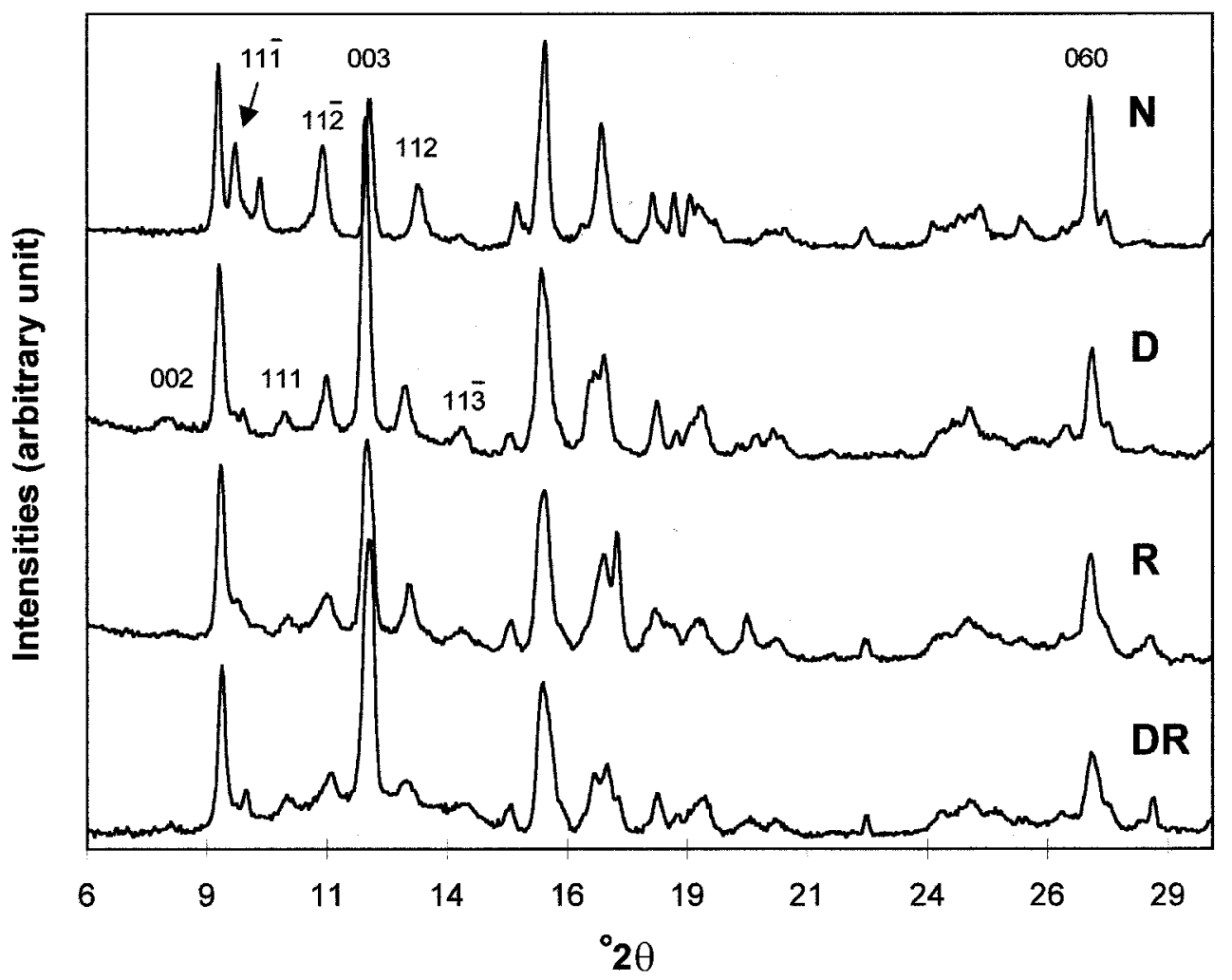

FIG. 5. XRD pattern $(\lambda-K \alpha$ Mo $=0.70926 \AA)$ of celadonite 69 , in natural $(\mathrm{N})$, dehydroxylated (D), rehydroxylated (R) and de-rehydroxylated (DR) states. Layers are trans-vacant in the $\mathrm{N}$ specimen, but cis-vacant in the others (from Muller et al., 1999). 
while the rehydroxylation of glauconite (with a high $\mathrm{Al}$ content) is accompanied by the reverse cation migration, which restores the $t v$ layers, and indicates that the migration process probably depends on the cation composition. A last case is that of $c v$ Al-rich minerals (like montmorillonites). The work of Muller et al. (1999b), based on DTA, showed that the octahedral cations also migrate during dehydroxylation, the layers becoming $t v$, and remaining $t v$ after rehydroxylation. The role of the chemical composition seems to be prominent in the $c v / t v$ transformations caused by dehydroxylationrehydroxylation processes.

\section{Order-disorder in layer stacking}

The stacking of the layers in 1:1 clay minerals (kaolin subgroup) can be modified, e.g. by the intercalation of water or organic molecules. Intercalation was studied in kaolinite by Thomson \& Cuff (1985), Costanzo et al. (1984) and Bookin et al. (1992), in dickite by Bookin et al. (1992), but not in the third member of the subgroup i.e. nacrite. Ben Haj Amara et al. $(1998,1999)$ considered this mineral in order: (1) to determine the role of the polytypism, and then of the stacking of the layers, as a result of the intercalation; and (2) to determine accurately the position and orientation of the intercalated molecules in the interlayer space, in order to understand the role of the shape of the intercalated molecules in the layer stacking. This study has mainly used the XRD on powder and oriented samples, and the IR spectroscopy. The intercalated molecules were water, dimethylsulphoxide (DMSO) which has an isotropic shape, and $n$ methyl-acetamide (NMA) which is a planar molecule. The first information on the positions of the molecules and site occupancies has been obtained from mono-dimensional Fourier transform (MFT) analysis of XRD patterns for oriented specimens. Then, peak positions in powder XRD patterns have provided the starting values of the layer stacking. The modelling of the powder XRD patterns has been performed with modifications of the intercalated molecule orientation, compatible with MFT and IR spectra to provide the best fit with experimental data. It has been shown that water and DMSO molecules are trapped between the ditrigonal cavities of the tetrahedral sheet and the vacant octahedron of the adjacent layer (Fig. 6a), with a displacement between layers close to $-a / 3+b / 3$. The DMSO molecules occupy the same position as in kaolinite (Bookin et al., 1992). The NMA molecules are also trapped within the same environment, but due to the planar shape of the molecule, the translation between adjacent layers is $-0.24 a+0.20 b$ (Fig. 6b). Thus it is the shape of the molecule which seems to play the prominent role in the interlayer shift.

\section{Finite size of particles as a lattice disorder}

Clay mineral particles usually contain a rather small number of layers, the average values ranging from five to a few tens. The distribution of these sizes exists and is usually well described by a lognormal law (Drits et al., 1997b). Because the outer surfaces of particles comprise only a small part of the whole particle, it is generally assumed that their influence on spectroscopic and diffraction results is rather small. Three different programs exist for the simulation of the XRD patterns of two(and three-) component systems: the widely used NEWMOD program (Reynolds, 1985); that developed by Sakharov (1976, not published), used for the XRD intensity calculations described above; and the Plançon \& Drits program (1999) CALCMIX which performs the same calculation as the Sakharov program but with a different user interface. All these programs are based on the same Markovian statistics for the description of the stacking of the layers, but differ in the way these particles end, the NEWMOD formalism always assuming a 2:1 layer outer surface. The observation of non-negligible discrepancies in calculated intensities between NEWMOD and CALCMIX found their origin in the nature of the outer surfaces. This led to the design of a new formalism and of the corresponding computer program (Sakharov et al., 1999a), which allows the description of the XRD intensities for particles ending in any kind of conceivable surfaces. The first results are that, as expected, the role of the outer surfaces is greater when the mean size of the particles decreases, whatever the mineral under consideration. But even for particles composed of several tens of layers, the effect remains strong for some minerals (e.g. chlorites) (Fig. 7). This new domain of research, i.e. the determination of the outer surfaces by XRD, may help to understand the mechanisms of crystal growth, e.g. a layer-by-layer or screw dislocation growth. It may also be useful in understanding the surface reactivity of finely dispersed clay minerals. 
a

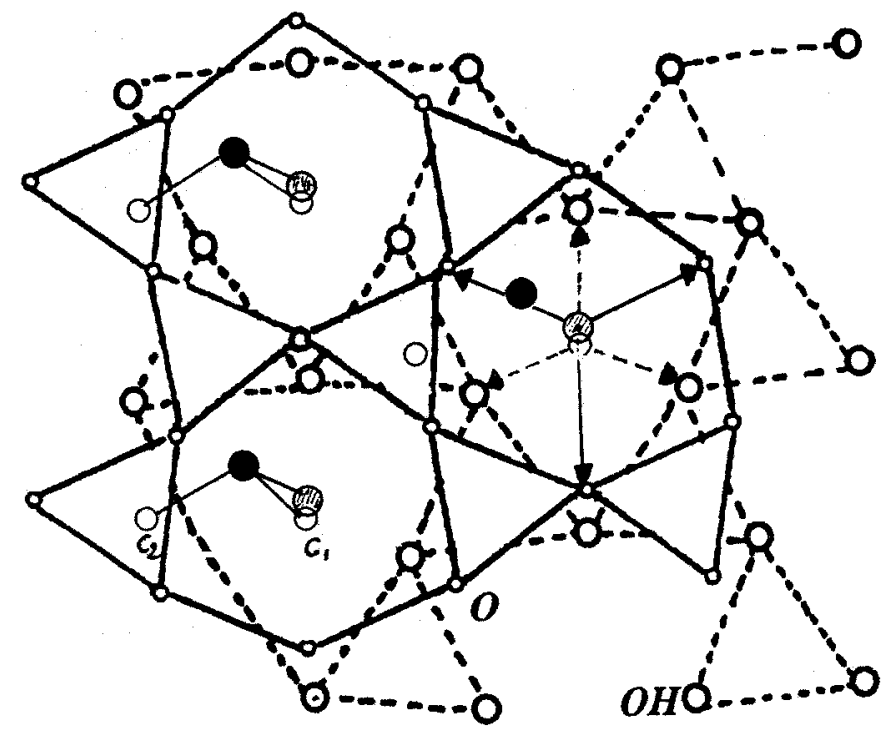

b

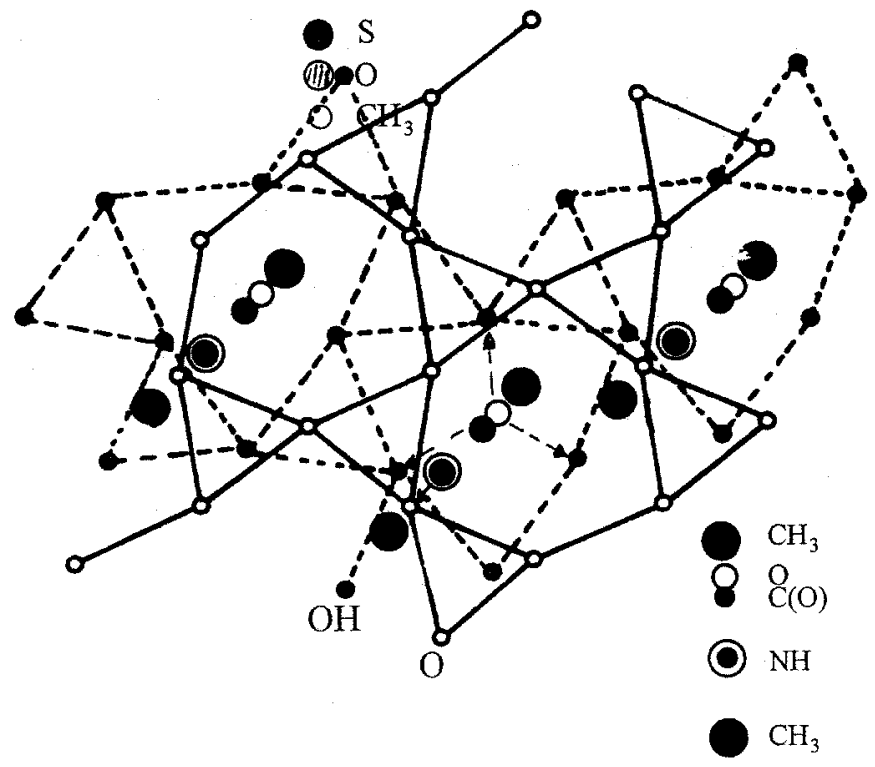

FIG. 6. Projection on the layer plane of the interlayer space of intercalated nacrite. Broken line: upper surface of the octahedral sheet of one nacrite layer; solid line: lower surface of the tetrahedral sheet of the adjacent nacrite layer; (a) DMSO; (b) NMA (from Ben Haj Amara et al., 1999).

\section{Heterogeneity as a disorder}

It is generally assumed that each clay mineral phase in a small size sample (a few grams) can be described by one set of structural parameters. Some exceptions exist, e.g. the expert system for the description of disordered kaolinites (Plançon \& Zacharie, 1990) is based on the assumption of a biphased system. Why does Birdwood kaolinite (South Australia) not intercalate easily with 


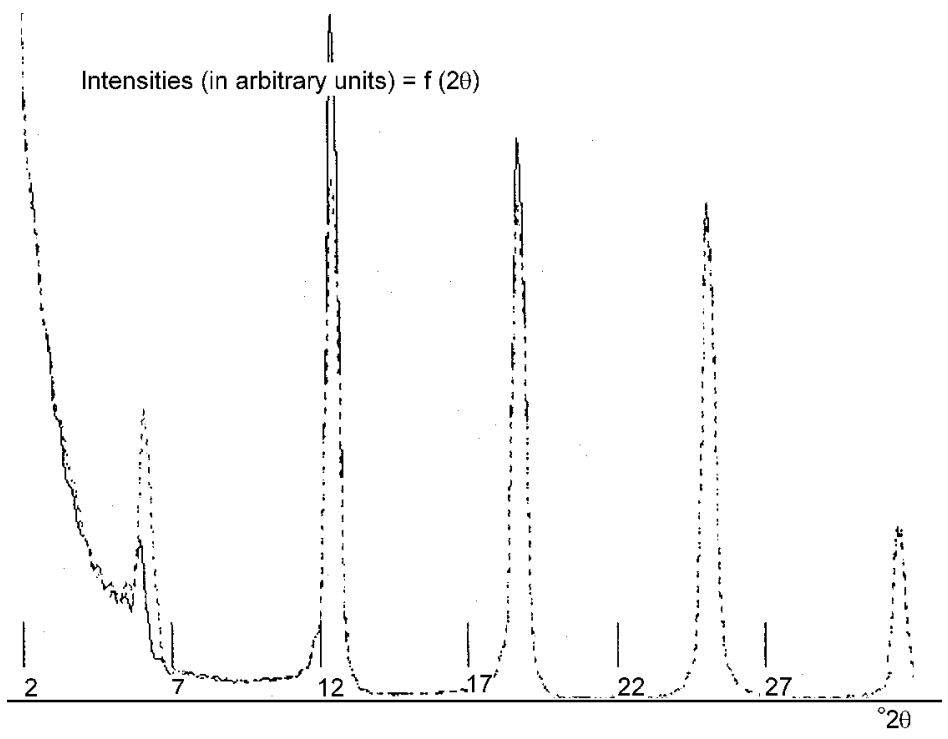

FIG. 7. Calculated XRD patterns for oriented samples of chlorite. Uniform distribution of the thickness of particles between 3 and 14 layers. All particles end with brucite layers on both outer surfaces (solid line) or with a brucite layer on one side and a 2:1 layer on the other side (dotted line) (from Sakharov et al., 1999a).

acetamide and formamide? It is well known that kaolinites with few stacking defects intercalate easily and almost completely with acetamide and formamide, whereas high-defect kaolinites intercalate less fully. The Birdwood kaolinite was studied by Frost et al. (1999). Based on the Hinckley index (1.35), this kaolinite is highly ordered but intercalates with difficulty (18 days for a $20 \%$ intercalation, and extended treatment never produces an intercalation over $60 \%$ ). Raman spectroscopy in the $\mathrm{OH}$-stretching region showed no change in the intensity yet the kaolinites were being intercalated. X-ray diffraction showed the presence of two phases of kaolinite, one highly ordered and one disordered. Minor dickite and two amorphous phases were also found. Electron microscopy shows the presence of two particle shapes attributed to the two kaolinites phases. The difficulty of intercalation is attributed to the coexistence of these two phases, the high-defect kaolinite apparently coating the highly ordered one at the edges, thereby preventing and slowing intercalation. Bish \& Chipera (1998) studied two standard kaolinites (KGa- 1 and API\#9) which could easily appear identical by XRD. The study of different size-fractions reveals, however, that all the fractions consist of at least two kaolinites, the smallest fraction containing the most disordered kaolinite for API\#9 (Fig. 8), which is the opposite to KGa-1. This remarkable dissimilarity suggests the possibility of a genetic relationship.

\section{CONCLUSIONS}

Recent work shows that the structural characterization of clay minerals becomes, with time, more and more precise and that the nature of the layers, their chemical composition and layer charge are now insufficient to describe clay mineral particles. But is greater precision necessary for practical use? Fortunately, the use of clay minerals has not waited for their accurate structural characterization. However, the utility of a clay material can often be predicted by a structural determination. For example, if the material is a kaolinite, and structural determination reveals that it is disordered, it would be wise to avoid using it for paper coating or intercalation of organic molecules. Nevertheless, a simple structural determination is sometimes insufficient. For example, the reactivity of clays in an intercalation process can be unexpected, (e.g. the kaolinite from Birdwood, mentioned above), and only an accurate structural study can show why, and tell if such problems are surmountable. In 


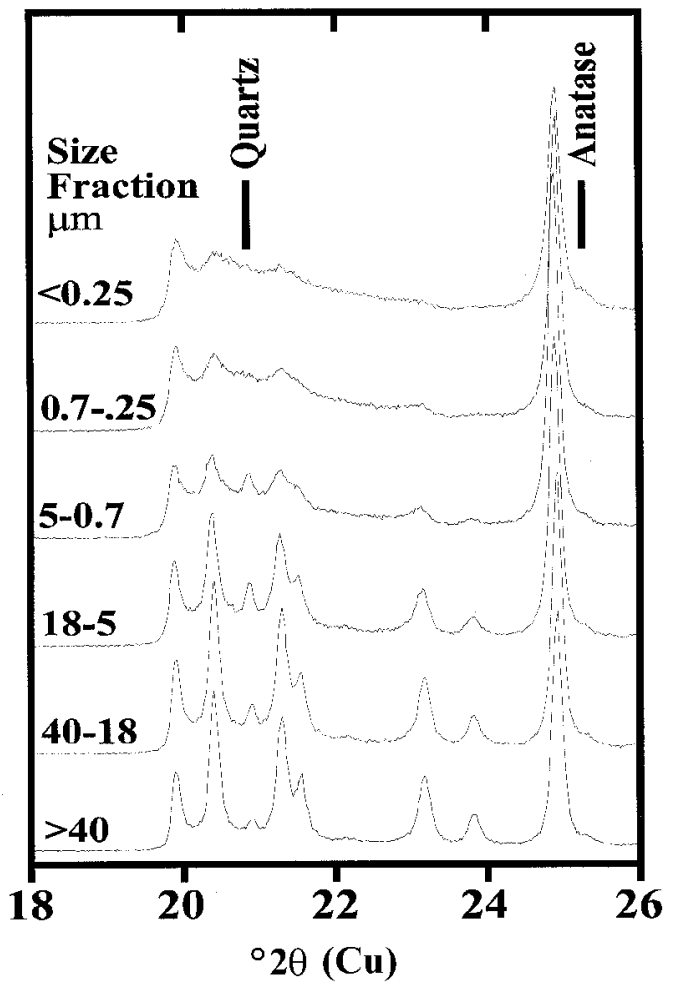

FIG. 8. X-ray diffraction patterns of six size-fractions of API\#9 kaolinite (from Bish \& Chipera, 1998).

another example: a manufacturer runs out of the clay he normally uses because the quarry is exhausted, or it is inhomogeneous, and the clay mineral extracted does not satisfy his requirements. In that instance, a precise characterization of the material is necessary to find an equivalent. It has also been shown how an XRD study of the structural occupancy of trans and cis sites of a material, or an HRTEM study of its mixed-layering can explain its origin and its transformations. These results are guides in the search for equivalent materials.

The practical benefits which may result from an accurate structural determination may also be illustrated in the context of the occurrence of oil. Drits et al. (1997) suspected that in the diagenetic transformation of the I-S-V clays of the North Sea shales, ammonium was supplied during oil occurrence to form the new non-expanding interlayers, which are pure ammonium tobelite. This assumption is now validated (Lindgreen et al., 2000). The illitization in oil source rocks is linked to oil generation. The I-S in these rocks contain $t v 2: 1$ layers and tobelite interlayers are formed through solid-state Al for $\mathrm{Si}$ substitution in the tetrahedral sheet and by ammonium fixation in the corresponding interlayers. This illitization deviates from the illitization in other rocks because of the supply of ammonium formed during oil generation and the fixation of this ammonium in the former smectite interlayers. This can be brought to the fore only by very precise structural study, as shown above.

Two conclusions concerning methodology are worth emphasizing: (1) accurate structural characterization can be obtained only if several complementary techniques are used (e.g. XRD and IR, EXAFS and Mössbauer spectroscopies, etc.); and (2) the limits of the experimental capabilities (e.g. HRTEM) or theoretical developments (e.g. formalism taking into account, in diffraction, the outer surface structures) have not been reached, and accurate structural characterization of clay minerals can be improved further.

\section{REFERENCES}

Altaner S.P. \& Ylagan R.F. (1997) Comparison of structural models of mixed-layer illite/smectite and reaction mechanisms of smectite. Clays Clay Miner. 45, 517-533.

Amouric M. \& Olives J. (1998) Transformation mechanisms and interstratification in conversion of smectite to kaolinite: an HRTEM study. Clays Clay Miner. 46, 521-527.

Bailey S.W., editor (1988) Hydrous Phyllosilicates (Exclusive of Micas). Reviews in Mineralogy, 19. Mineralogical Society of America, Washington, D.C. Bailey S.W., Banfield J.F., Barker W.W. \& Katchan G. (1995) Dozyite, a 1:1 regular interstratification of serpentine and chlorite. Am. Miner. 80, 65-77.

Banfield J.F. \& Bailey S.W. (1996) Formation of regularly interstratified serpentine-chlorite minerals by tetrahedral inversion in long-period serpentine polytypes. Am. Miner. 81, 79-91.

Banfield J.F., Bailey S.W. \& Barker W.W. (1994) Polysomatism, polytypism, microstructures and reaction mechanisms in serpentine and chlorite. Contrib. Mineral. Petrol. 117, 137-150.

Ben Haj Amara A., Ben Brahim J., Plançon A. \& Ben Rhaiem H. (1998) Etude de la structure d'une nacrite hydratée et dehydratée. J. Appl. Crystallogr. 31, 654-662.

Ben Haj Amara A., Plançon A., Ben Brahim J. \& Ben Rhaiem H. (1999) Intercalation of organic molecules and water in nacrite. P. 63 in: Abst. Conf. Eur. Clay Groups Assoc., Kraków. 
Besson G. \& Drits V.A. (1997a) Refined relationships between chemical composition of dioctahedral fine dispersed mica minerals and their infrared spectra in the OH-stretching region. Part I: Identification of the stretching bands. Clays Clay Miner. 45, 158-169.

Besson G. \& Drits V.A. (1997b) Refined relationships between chemical composition of dioctahedral fine dispersed mica minerals and their infrared spectra in the OH-stretching region. Part II: The main factors affecting $\mathrm{OH}$ vibration and quantitative analysis. Clays Clay Miner. 45, 170-183.

Bish D.L. \& Chipera S.J. (1998) Variation of kaolinite defect structure with particle size. Abst. Ann. Meet. Clay Miner. Soc., Cleveland.

Bookin A.S., Drits V.A. \& Tcherkachin V.I. (1992) Structural modifications of kaolinite and dickite by intercalation. Izv. Acad. Nauk, Ser. Geol. 4, 106-118 (in Russian).

Brindley G.W. \& Brown G., editors (1980) Crystal Structures of Clay Minerals and their X-ray Identification. Monograph, 5. Mineralogical Society, London.

Costanzo P.M., Giese R.F. \& Lipsicas M. (1984) Static and dynamic structure water in hydrated kaolinite. I - The static structure. Clays Clay Miner. 32, $549-551$.

Cuadros J. \& Altaner S.P. (1998) Compositional and structural features of the octahedral sheet in mixedlayer illite/smectites from bentonites. Eur. J. Mineral. 10, 111-124.

Dainyak L.G., Drits V.A. \& Heifits L.M. (1992) Computer simulation of cation distribution in dioctahedral 2:1 layer silicates using IR-data: Application to Mössbauer spectroscopy of a glauconite sample. Clays Clay Miner. 40, 470-479.

Deconinck J.F. \& Chamley H. (1995) Diversity of smectite origins in Late Cretaceous sediments: Examples of chalks from Northern France. Clay Miner. 30, 365-379.

Drits V.A. (1966) Some structural features of layer silicates with long periodicity along $\mathrm{c}$ axis. Pp. 35-45 in: Physical Methods for Study of Sedimentary Rock Minerals (A.G. Kossovskaya, editor). Nauka, Moscow (in Russian).

Drits V.A. \& McCarty D.K. (1996) The nature of diffraction effects from I and I-S consisting of interstratified tv and $\mathrm{cv}$ layers. Am. Miner. 81, $852-863$.

Drits V.A. \& Sakharov B.A. (1976) X-ray Analysis of Mixed-Layer Minerals. Nauka, Moscow (in Russian).

Drits V.A. \& Tchoubar C. (1990) X-ray Diffraction by Disordered Lamellar Structures. Springer Verlag, Berlin.

Drits V.A., Varaxina T.V., Sakharov B.A. \& Plançon A. (1994) A simple technique for identification of onedimensional powder X-ray diffraction patterns for mixed-layer illites-smectites and other interstratified minerals. Clays Clay Miner. 42, 382-390.

Drits V.A., Lindgreen H. \& Salyn A. (1997a) Determination of the content and distribution of fixed $\mathrm{NH}_{4}$ in illite-smectite by $\mathrm{X}$-ray diffraction: Application to North Sea illite-smectite. Am. Miner. 82, 79-87.

Drits V.A., Środoń J. \& Eberl D.D. (1997b) XRD measurement of mean crystallite thickness of illite/ smectite: reappraisal of the Kubler index and the Scherrer equation. Clays Clay Miner. 45, 461-475.

Drits V.A., Sakharov B.A., Lindgreen H. \& Salyn A. (1997c) Sequential structure transformation of illitesmectite-vermiculite of Upper Jurassic shales from the North Sea and Denmark. Clay Miner. 32, 351-371.

Drits V.A., Dainyak L.G., Muller F., Besson G. \& Manceau A. (1997d) Isomorphous cation distribution in celadonites, glauconites and Fe-illites determined by infrared, Mössbauer and EXAFS spectroscopies. Clay Miner. 32, 153-179.

Drits V.A., Lindgreen H., Salyn A., Ylagan R. \& McCarty D.K. (1998) Semiquantitative determination of trans-vacant and cis-vacant 2:1 layers in illites and illite-smectites by thermal analysis and X-ray diffraction. Am. Miner. 83, 1188-1198.

Frost R.L., Van der Gaast S.J., Paroz G.N., Zbik M. \& Kloproge J.T. (1999) Why Birdwood kaolinite (South Australia) does not intercalate with acetamide and formamide? P. 85 in: Abst. Conf. Eur. Clay Groups Assoc., Kraków.

Güven N. (1991) On the definition of illite/smectite mixed-layer. Clays Clay Miner. 39, 661-662.

Jakobsen H.J., Nielsen N.C. \& Lindgreen H. (1995) Sequences of charged sheets in rectorite. Am. Miner. 80, 247-252.

Lindgreen H., Drits V.A., Sakharov B.A., Salyn A.L., Wrang P. \& Dainyak L.G. (2000) Illite-smectite structural changes during metamorphism in black Cambrian Alum shales from the Baltic Sea. Am. Miner. 85, 1223-1238.

Manceau A., Bruno B., Drits V.A., Chategner D., Gates W.P., Wu J., Huo D.\& Stucki J.W. (2000) Oxidationreduction mechanism of iron in dioctahedral smectites: I Crystal chemistry of oxidized reference nontronite. Am. Miner. 85, 133-152.

Moore D.M. \& Reynolds R.C. (1989) X-ray Diffraction and the Identification and Analysis of Clay Minerals. Oxford University Press, Oxford.

Muller F., Besson G., Manceau A. \& Drits V.A. (1997) Distribution of isomorphous cations within octahedral sheets in montmorillonite from Camp-Berteaux. Phys. Chem. Miner. 24, 159-166.

Muller F., Plançon A. \& Drits V.A. (1999a) Structure of dehydroxylated and rehydroxylated dioctahedral 2:1 layer silicates. P. 114 in: Abst. Conf. Eur. Clay Groups Assoc., Kraków. 
Muller F., Plançon A. \& Drits V.A. (1999b) Application of the structural models of heat-treated micas to the study of the dehydroxylation-rehydroxylation of smectites. Abst. Colloque RX99, Strasbourg.

Muller F., Drits V.A., Plançon A. \& Besson G. (2000a) Dehydroxylation of $\mathrm{Fe}^{3+}$, Mg-rich dioctahedral micas: (I) Structural transformation. Clay Miner. 35, 491-504.

Muller F., Drits V.A., Tsipurski S.I. \& Plançon A. (2000b) Dehydroxylation of $\mathrm{Fe}^{3+}$, Mg-rich dioctahedral micas: (II) Cation migration. Clay Miner. 35, 505-514.

Plançon A. \& Zacharie C. (1990) An expert system for structural characterization of kaolinites. Clay Miner. 25, 249-260.

Plançon A. \& Drits, V.A. (1999) Software for X-ray phase analysis of clays. P. 121 in: Abst. Conf. Eur. Clay Groups Assoc., Kraków.

Reynolds R.C. (1980) Interstratified clay minerals. Pp. 249-304 in: Crystal Structures of Clay Minerals and their X-ray Identification (G.W. Brindley \& G. Brown, editors). Monograph, 5. Mineralogical Society, London.

Reynolds R.C. (1985) NEWMOD a computer program for calculation of one-dimensional diffraction patterns of mixed-layer clays. R.C. Reynolds, 9 Brook Rd. Hanover, NH 03755, USA.

Reynolds R.C. (1988) Mixed-layer chlorite minerals. Pp. 601-630 in: Hydrous Phyllosilicates (Exclusive of Micas) (S.W. Bailey, editor). Reviews in Mineralogy, 19. Mineralogical Society of America, Washington, D.C.

Reynolds R.C. \& Hower J. (1970) The nature of interlayering in mixed-layer illite-montmorillonite. Clays Clay Miner. 18, 25-36.

Sakharov B.A., Plançon A. \& Drits V.A. (1999a) Influence of outer surface structure of crystals on X-ray diffraction. P. 129 in: Abst. Conf. Eur. Clay Groups Assoc., Kraków.

Sakharov B.A., Lindgreen H., Salyn A. \& Drits V.A. (1999b) Determination of illite-smectite structures using multispecimen X-ray diffraction profile fitting. Clays Clay Miner. 47, 555-566.

Schultz L.G., Shepard A.O., Blackmon P.D. \& Starkey H.C. (1971) Mixed-layer kaolinite-montmorillonite from the Yucatan Peninsula, Mexico. Clays Clay Miner. 19, 137-150.

Slonimskaya M.V., Besson G., Dainyak L.G., Tchoubar
C. \& Drits V.A. (1986) Interpretation of the IR spectra of celadonites and glauconites in the region of the $\mathrm{OH}-$ stretching frequencies. Clay Miner. 21, $377-388$.

Środoń J. (1980) Precise identification of illite/smectite in interstratifications by X-ray powder diffraction. Clays Clay Miner. 28, 401-411.

Środoń J. (1981) X-ray identification of randomly interstratified illite/smectite in mixtures with discrete illite. Clay Miner. 16, 297-304.

Środoń J. (1984) X-ray powder diffraction identification of illitic materials. Clays Clay Miner. 32, 337-349.

Sudo T. \& Hayashi H. (1956) A randomly interstratified kaolinite-montmorillonite in acid clay deposit in Japan. Nature 178, 1115-1116.

Sudo T., Hayashi H. \& Shimoda S. (1962) Mineralogical problems of intermediate clay minerals. Clays Clay Miner. 9, 378-392.

Tettenhorst R. \& Johns W.D. (1966) Interstratification in montmorillonite. Clays Clay Miner. 13, 85-93.

Thomas A.R. (1989) A new mixed-layer clay mineral. Regular 1:1 mixed-layer kaolinite-smectite. P. 69 in: Abst. Ann. Meet. Clay Miner. Soc. Sacramento, California.

Thomson J.G. \& Cuff C. (1985) Crystal structure of kaolinite dimethylsulfoxide intercalate. Clays Clay Miner. 33, 490-500.

Tomita K., Takahashi H. \& Watanabe T. (1988) Quantification curves for mica/smectite interstratifications by X-ray powder diffraction. Clays Clay Miner. 36, 258-262.

Tsipurski S.I. \& Drits V.A. (1984) The distribution of octahedral cations in the 2:1 layers of dioctahedral smectites studied by oblique-texture electron diffraction. Clay Miner. 19, 177-193.

Udagawa S., Urabe K. \& Hasu H. (1974) The crystal structure of muscovite dehydroxylate. Japan Ass. Miner. Petrol. Econ. Geol. 69, 381-389.

Watanabe T. (1981) Identification of interstratifications of illite and montmorillonite by X-ray powder diffraction. J. Miner. Soc. Japan, 15, 32-41 (in Japanese).

Watanabe T. (1988) Structural model of illite/smectite interstratified minerals and the diagram for their interstratification. Clay Sci. 7, 97-114.

Wiewiora A. (1971) A mixed-layer kaolinite-smectite from Lower Silesia, Poland. Clays Clay Miner. 19, 415-416. 